\title{
Epigenética e exercício físico: influência em transtornos de ansiedade?
}

\section{Epigenetics and physical exercise: influence in anxiety disorders?}

\author{
Mariana de Oliveira Lobo ${ }^{1}$ (orcid.org/0000-0003-0703-7140), Felipe Carneiro Krier ${ }^{1}$ orcid.org/0000-0003-0537-1321), \\ Ramires Alsamir Tibana² (orcid.org/0000-0003-0124-0826), Jonato Prestes ${ }^{3}$ (orcid.org/0000-0003-0399-8817)
}

1. Discente do curso de Medicina da Universidade Católica de Brasília (UCB), Brasília, DF, Brasil. 2. Pós-doutorando pela Universidade Federal do Mato Grosso (UFMT), Cuiabá, MT, Brasil. 3. Docente do Programa de Pós-graduação em Educação Física da Universidade Católica de Brasília (UCB), Brasília, DF, Brasil.

\begin{abstract}
Resumo
Introdução: A embora o número de estudos que correlacionam os efeitos da atividade física com aspectos morfofisiológicos cerebrais e com transtornos de ansiedade tenha crescido, existe limitação no campo do treinamento de força (TF) e seu papel de modificador comportamental, assim como sua relação com eventos epigenéticos. Objetivo: realizar uma revisão sistemática da literatura em relação aos efeitos do exercício físico e à influência transgeracional das características epigenéticas em quadros de transtornos de ansiedade. Métodos: realizou-se uma pesquisa bibliográfica em Literatura científica nacional e internacional, nas bases eletrônicas: Literatura Latino-Americana em Ciências da Saúde (LILACS), Scientific Electronic Library Online (SciELO) e Public Medline (PubMed). Na busca, sem limitação de período de tempo, utilizaram-se as seguintes palavras-chave, em português/inglês: "Ansiedade”; "Ansiedade e exercício físico"; "Treino de força e Transtorno de Ansiedade"; "Transtorno do Pânico"; "Transtorno de Ansiedade Generalizada”; "Epigenética”. Resultados: notou-se que, nos quadros de transtornos de ansiedade, os ajustes fisiológicos aos quais o organismo se torna submetido extrapolam o âmbito do sistema nervoso autônomo e atingem o sistema endócrino e imunitário, tornando-se duradouro. A prática de exercício físico e a epigenética demonstraram relevante papel na modificação dos principais sinais e sintomas dessa psicopatologia. Conclusões: os artigos estudados apresentaram tipos de estudo bastante distintos entre si, demonstrando o benefício alcançado pela prática de exercício físico nos quadros de transtorno de ansiedade, mas não possibilitaram delinear que tipos e metodologias são os mais adequados. Ficou evidente a necessidade da correlação entre Treinamento de força e epigenética.
\end{abstract}

Palavras-chave: Treinamento de força. Exercício físico. Epigenética. Transtorno de Ansiedade.

\begin{abstract}
Introduction: Although the number of studies that correlate the effects of physical activity with brain morphophysiological aspects and anxiety disorders have grown in recent years, there is great limitation in the strength training (ST) field and its role as the modifier of such behaviors. Objective: to conduct a systematic review of the literature regarding the effects of physical exercise and the trans-generational influence of epigenetic characteristics in cases of anxiety disorders. Methods: A bibliographic research held in national and international scientific literature was carried out in the following electronic databases: Latin American Literature in Health Sciences (LILACS), Scientific Electronic Library On-line (SciELO) and Public Medline (PubMed). The search, without time limitation, used the following key words: "Anxiety"; "Anxiety and exercise"; "Strength training and Anxiety Disorder"; "Panic Disorder"; "Generalized Anxiety Disorder"; "Epigenetics". Results: In the anxiety disorder frames, some physiological adjustments which the body is subjected to undergo beyond the scope of the autonomic nervous system affecting the endocrine and immune systems, making them durable, were observed. The practice of physical exercises and epigenetics have shown important role in modifying the course of the main signs and symptoms that involves this psychopathology. Conclusions: The study criteria in the articles selected in the present research were quite distinct from each other. It was possible to demonstrate the benefit achieved by physical exercise on anxiety disorder frames, but it was not possible to delineate which types or methods are the best suited. The need for researches in the strength training (ST) field and trans-generational transmission became evident.
\end{abstract}

Keywords: Oxygen therapy. Nursing. Knowledge.

\section{INTRODUÇÃO}

Nos últimos anos, o avanço tecnológico assim como as pressões sociais, políticas e econômicas têm contribuído para o aumento de problemas mentais de ordem emocional ${ }^{1} \mathrm{e}$ é, nesse contexto, que se encontra a presente revisão. Sabe-se que, em situações emocionais, o ser humano pode experimentar basicamente três emoções principais em resposta a uma situação ameaçadora: raiva dirigida para fora (o equivalente à cólera), raiva dirigida contra si mesmo (depressão) e ansiedade ou medo'. A ansiedade ocasional é parte normal da vida. Assim, um indivíduo pode sentir-se ansioso quando confrontado com um problema no trabalho, antes de fazer um teste ou tomar uma decisão importante.

Encontrando-se em estado de alerta, o organismo reage com um comportamento de fuga ou de ataque ao agente estressor. Tal reação, ainda que seja exacerbada com uma descarga de hormônios mais elevada, poderá ser considerada normal se, logo após essa fase de excitação, retornar a seu estado de 
equilíbrio. No entanto, essa fase pode perdurar, envolvendo outros processos internos até a exaustão. Desenvolve-se, então, uma patologia como, por exemplo, os transtornos de ansiedade ${ }^{2}$.

Os transtornos de ansiedade extrapolam a preocupação e o medo temporários. Frequentemente, não vão embora e podem piorar com o tempo, interferindo direta e indiretamente nas atividades diárias do trabalho, da escola e dos relacionamentos ${ }^{2}$. Diferentemente da ansiedade momentânea, causada por um evento específico (como falar em público ou em um primeiro encontro), a ansiedade grave dura pelo menos seis meses e geralmente requer avaliação e tratamento ${ }^{2}$. Cada transtorno de ansiedade apresenta uma sintomatologia específica, mas há uma tendência à aglomeração em torno do medo excessivo e irracional e do pavor ${ }^{3}$.

A sociedade contemporânea, notada pela exacerbação dos fenômenos ansiosos supracitados bem como pela forte associação entre fatores ambientais/ inatividade física e a emergência e prevalência de doenças crônicas, tem sido alvo de diversas discussões no campo sociocientífico. Diferentes setores têm discutido sobre a necessidade da melhora da qualidade de vida da população e, entre os fatores mais listados, está o impacto positivo do exercício físico - tanto ao nível da saúde física, quanto da saúde mental ${ }^{4}$.

O estilo de vida ativo e a prática regular de atividade física apresentam-se como métodos eficazes na redução do risco de doenças cardiovasculares, obesidade, diabetes e hipertensão arterial, bem como na obtenção de benefícios psicológicos. Entre eles, o controle dos níveis de ansiedade e de stress e a redução dos estados depressivos ${ }^{5}$.

A atividade física é um excelente meio de descarregar as tensões acumuladas pelas pressões e exigências da vida moderna, em sociedades marcadas, cada vez mais, pela alta competitividade. O caráter, a frequência e a intensidade do exercício físico são pontos divergentes entre diversos autores. Becker (2000, cit. por Veigas, 2009) refere que é necessária a prática de exercício físico de intensidade moderada, entre quatro e 20 semanas, para que sejam obtidos efeitos substanciais na área emocional. Nível severo de atividade física tem sido associado a efeitos afetivos negativos e maiores ocorrências de ataques de pânico em indivíduos com Transtorno de Ansiedade 5 . Nesse sentido, é necessário que haja prudência quanto à prescrição de exercício físico como terapia, ainda que de intensidade leve a moderada, em um treino progressivo e controlado. ${ }^{2}$

Nessa conjuntura, a prática regular do treinamento de força (TF) tem sido indicada como uma alternativa não farmacológica eficaz no combate de doenças cardiovasculares, por diversas organizações de saúde: American College of Sports, American Heart Association e Sociedade Brasileira de Hipertensão ${ }^{5}$. Além disso, o mesmo vem sendo relatado como um importante componente para a prevenção de todas as causas de mortalidade. Grontved et al. (2013, cit. por Veigas, 2009) demonstraram que baixos níveis de força muscular em jovens estão associados a valores altos de triglicerídeos, pressão arterial, lipoproteína de alta densidade (LDH) e elevação do risco de desenvolver sobrepeso/obesidade na fase adulta? ${ }^{7}$.

De forma análoga, Ortega et al. (2012, cit. por Tibana, 2013) reportaram que o declínio da força muscular em adolescentes está associado a suicídio prematuro (< 55 anos), doenças cardiovasculares e câncer ${ }^{7}$. Ademais, jovens com essas características apresentam um risco 20 a 35\% de mortalidade por qualquer causa de doença cardiovascular na vida tardia, independentemente do índice de massa corporal e pressão arterial sanguínea7.

O segundo ponto-base que fundamenta a ideia central aqui apresentada é a epigenética. Inicialmente, sob o olhar genético, entende-se que variações na sequência de DNA são responsáveis, em última instância, pela determinação de quais, quanto e quando um conjunto de proteínas será expresso em um determinado tipo celular e, por consequência, em determinado tecido. Existe, entretanto, algo além das variações na sequência de DNA que é capaz de interferir e coordenar a expressão gênica: a epigenética ${ }^{8}$.

Os mecanismos epigenéticos atuam na cromatina (DNA e histonas) e não somente no DNA. Do ponto de vista molecular, os mecanismos epigenéticos são capazes de interferir na expressão gênica modificando quimicamente o DNA e as histonas, sem alterar a sequência de DNA. Em síntese, a definição molecular de epigenética seria o conjunto de alterações na cromatina que, coletivamente, estabelecem e propagam diferentes padrões de expressão gênica (transcrição) e de silenciamento em um mesmo genoma ${ }^{9}$. O fenômeno epigenético promove mudanças que podem persistir por uma ou mais gerações e evidencia o fato de que hábitos de vida podem modificar o funcionamento de genes, expressão de proteína, conformação da cromatina e metilação do DNA ${ }^{10}$.

Diante do exposto, este trabalho tem por objetivo realizar uma revisão de literatura em relação aos efeitos do exercício físico nos transtornos de ansiedade, bem como demonstrar a necessidade de estudos que abordem a influência transgeracional das características epigenéticas em quadros neuropsiquiátricos.

\section{MÉTODOS}

Trata-se de estudo retrospectivo observacional qualitativo e quantitativo. Realizou-se pesquisa bibliográfica em Literatura científica nacional e internacional, nas seguintes bases eletrônicas: MEDLINE (Medical Literature Analysis and Retrieval System Online /PubMed), LILACS (Literatura científica e técnica da América Latina e Caribe/BVS Biblioteca Virtual em Saúde) e SciELO (Scientific Electronic Library Online). Na busca, sem limitação de período de tempo, utilizaram-se as seguintes palavras-chave, conforme descritores em Ciências da Saúde (DeCS) em português: "Ansiedade"; "Ansiedade e exercício físico"; "Treino de força e Transtorno de Ansiedade"; "Transtorno do Pânico"; "Transtorno de Ansiedade Generalizada"; "Epigenética" em inglês: "Anxiety"; "Anxiety and exercise"; 
"Strength training and Anxiety Disorder"; "Panic Disorder"; "Generalized Anxiety Disorder"; "Epigenetics".

A seleção dos artigos incluiu, primeiramente, a leitura dos resumos das publicações encontradas, com o objetivo de refinar a amostra por meio de critérios de inclusão e exclusão. Os critérios de inclusão para a análise foram: tipo de publicação - artigos em periódicos; artigos no idioma inglês e português e artigos que utilizaram o exercício físico como intervenção em indivíduos com transtorno de ansiedade. Os critérios de exclusão foram: artigos sem abstract ou com ele em outra língua que não o inglês e/ou português; artigos que tratavam apenas de outras terapias complementares aos quadros de transtornos ansiosos que não especificamente os efeitos do exercício físico, artigos que tratavam de outras doenças/ transtornos mentais que não incluíssem quadros ansiosos.

Figura 1 - Fluxograma do processo de seleção dos artigos.

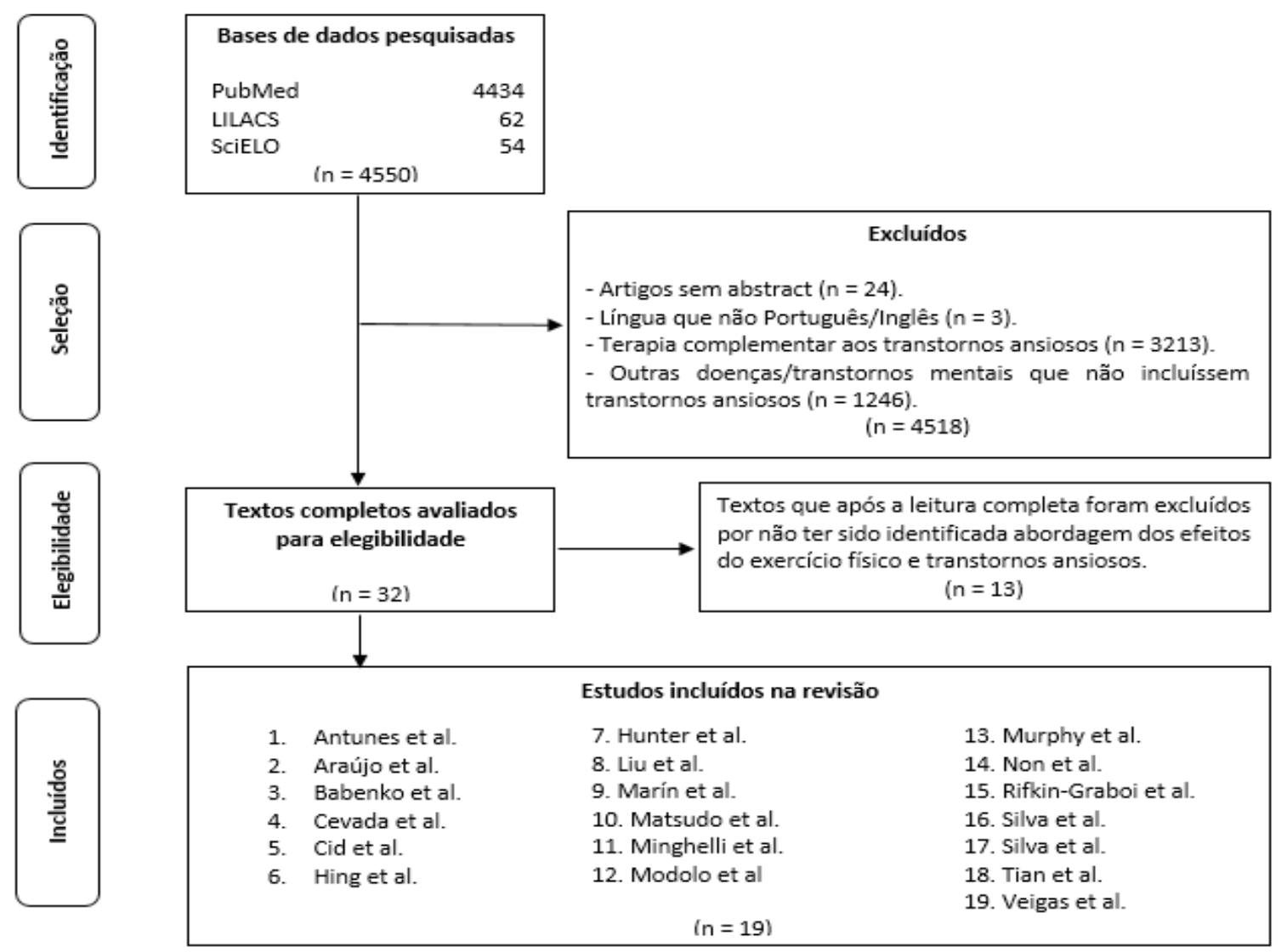

A avaliação crítica dos artigos consistiu na leitura de cada estudo na íntegra e, em seguida, na elaboração de quadros-síntese com os dados e as informações coletados de cada pesquisa, a saber: autores/data, amostra, aspectos metodológicos e principais resultados sobre os quadros de transtornos ansiosos. De forma auxiliar, utilizou-se a técnica de análise temática de conteúdo por meio da leitura e releitura dos resultados dos estudos, procurando identificar aspectos relevantes que se repetiam ou se destacavam (Figura 1).

\section{RESULTADOS}

\section{Exercício Físico e Quadros de Ansiedade}

O termo ansiedade geralmente é reservado a um estado de tensão ou apreensão cujas causas não são necessariamente produtoras de medo, mas sim da expectativa de alguma coisa (nem sempre ruim) que acontecerá no futuro próximo ${ }^{11}$. De acordo com o Manual Diagnóstico e Estatístico de Transtornos Mentais 5 (DSM- 5), medo é a resposta emocional à ameaça iminente real ou percebida enquanto a ansiedade é a antecipação de ameaça futura associada à tensão muscular e aos comportamentos de cautela ou esquiva. Os quadros de transtornos de ansiedade compartilham características de medo e ansiedade excessivos e perturbações comportamentais relacionadas.

Transtornos de ansiedade ocorrem com mais frequência em indivíduos do sexo feminino que em indivíduos do sexo masculino. Muitos se desenvolvem na infância e tendem a persistir se não forem tratados. Diversos elementos têm sido interpretados como importantes integrantes dentro da fisiopatologia e dos desdobramentos dos transtornos de ansiedade $^{11}$ (Figura 2).

Entre esses elementos, a prática de exercícios físicos tem apresentado correlação positiva com os casos de quadros 
ansiosos. Veigas et al. (2009) ${ }^{6}$, ao analisarem 207 indivíduos com idade média de 34,1 anos, reforçaram a hipótese de que a prática de exercício físico promove a diminuição dos níveis de ansiedade e depressão. De forma análoga, Cid et al. $(2007)^{12}$ demonstraram que, em uma amostra de 70 indivíduos, predominantemente feminina $(95,71 \%)$, com uma média de

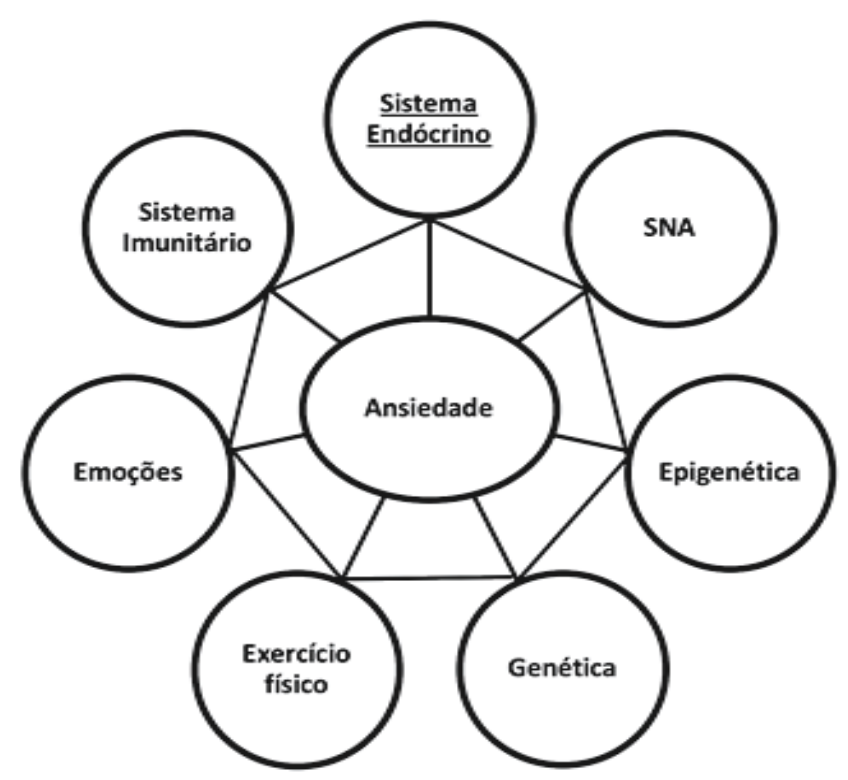

do exercício físico têm sido descritos como: melhora da função cerebral, restabelecimento de habilidades mentais, aprimoramento da função cognitiva e prevenção das disfunções psiquiátricas.

Quadro 1. Síntese das alterações associadas ao exercício
36,9 anos de idade, valores altos dos estados positivos de humor e baixos níveis de depressão foram encontrados para aqueles que praticam exercício físico.

Há evidências de que a prática de exercício físico regular modula diferentes funções cerebrais. Os benefícios neuroprotetores

\begin{tabular}{|lllll|}
\hline Estudo & Amostra & Idade média & Exercício & Alteração morfofisiológica cerebral \\
\hline Antunes et al. & $23 \mathrm{~S}$ & 66.97 anos & Aeróbico & Ansiedade/Depressão \\
Araújo et al. & $\mathrm{NE}$ & $\mathrm{NE}$ & Aeróbico & Ansiedade \\
Cevada et al. & $32 \mathrm{AT} / 30 \mathrm{NAT}$ & $\mathrm{NE}$ & $\mathrm{NE}$ & Melhora psicol'gica \\
Cid et al. & $3 \mathrm{H} / 67 \mathrm{M}$ & 36,9 anos & $\mathrm{NE}$ & Depressão/Humor \\
Marín et al. & $67 \mathrm{~S} / 67 \mathrm{PA}$ & $\mathrm{NE}$ & Alongamento & Ansiedade \\
Matsudo et al & $\mathrm{NE}$ & $\mathrm{NE}$ & Treinamento de força & Estresse/insônia \\
Minghelli et al & $38 \mathrm{~S} / 34 \mathrm{PA}$ & $\mathrm{Idosos}$ & Aeróbico & Ansiedade/Depressão \\
Modolo et al. & $36 \mathrm{AP} / 80 \mathrm{AA}$ & $\mathrm{NE}$ & NE & Humor/Qualidade de vida \\
Silva et al. & $\mathrm{Ratos}$ & $\mathrm{NE}$ & Aeróbico & Sem alterações \\
Silva et al. & $38 \mathrm{H} / 41 \mathrm{M}$ & 24 anos & Aeróbico & Sem ansiedade \\
Tian et al. & $\mathrm{NE}$ & Jovem e Idoso & Aeróbico & Morfofuncional \\
Veigas et al. & $102 \mathrm{H} / 105 \mathrm{M}$ & 34,1 anos & NE & Ansiedade/Depressão \\
\hline
\end{tabular}

Legenda: H- Homem; M - Mulher; S - sedentário; PA - Praticante de Atividade física; AP - Atleta profissional; AA -Atleta amador; AT - atleta; NAT - Não atleta, NE - Não especificado.

morfofisiológicas cerebrais foram identificadas e associadas à redução do estresse (8,3\%) - medo crônico, cuja causa geradora é identificável ${ }^{11}$, da insônia (8,3\%) e da depressão (33,3\%).

Houve variação significativa nos grupos amostrais selecionados, bem como nas idades dos indivíduos participantes das pesquisas. Dos grupos representativos de estudo, três não especificaram a amostra (com relação ao gênero e ao condicionamento físico).
Entre os estudos que buscaram correlacionar o exercício físico aos quadros de transtorno de ansiedade, $50 \%$ deles (Quadro 1 ) demonstraram melhora dos níveis ansiolíticos quando da prática de atividades aeróbicas e de alongamento. Outras alterações
- Aumento da atividade simpática.

IAM

Úlceras gástricas.

Queda da resistência

imunológica.
Dos nove restantes, o estudo de Veigas et al. (2009) ${ }^{6}$ apresentou a maior amostra populacional, incluindo 102 homens e 105 mulheres. No quesito idade, Silva et al. (2007) ${ }^{12}$ trouxeram avaliação de indivíduos com idade mais jovem - média de 14 anos, enquanto Antunes et al. (2005) ${ }^{4}$ marcaram o estudo de indivíduos com a média de idade mais elevada - 66,97 anos.

Apenas Matsudo et al. (2000) $)^{13}$ foram capazes de associar o 
treinamento de força (método específico de condicionamento físico que envolve o uso progressivo de cargas, bem como de diferentes modelos e métodos de treinamento) à melhora dos aspectos psicológicos associados à saúde mental durante o processo de envelhecimento.

\section{Quando a influência é epigenética}

A epigenética é chave tanto para a melhor compreensão da etiologia e da patologia dos distúrbios psiquiátricos, como de seus subtipos ou endofenótipos ${ }^{14}$. Por exemplo, é sabido que mecanismos epigenéticos, conquanto em resposta a experiências estressantes e a fatores ambientais hostis, estão potencialmente associados a maiores riscos de esquizofrenia, transtorno de hiperatividade do déficit de atenção, autismo, ansiedade e distúrbios relacionados à depressão mais tarde na vida, porque envolvem a expressão de miRNA e metilação do DNA tanto na placenta quanto no cérebro ${ }^{15}$.

Em conformidade, estudos epidemiológicos em humanos e pesquisas experimentais em animais recentes indicam que experiências estressantes no útero ou durante o início da vida podem aumentar o risco de doenças neurológicas e psiquiátricas, possivelmente via regulação epigenética alterada ${ }^{15}$.

Corroborando essa ideia, Rifkin-Graboi et al. (2015) ${ }^{16}$ avaliaram microestruturas neuronais de recém-nascidos por meio de um tensor de difusão, para verificar a variação da microestrutura neonatal em relação à ansiedade pré-natal, e analisaram o comportamento socioemocional infantil na idade de um ano. Segundo os autores, nessa avaliação, a ansiedade materna pré-natal previu anisotropia fracionada de importantes regiões responsáveis por respostas cognitivas e emocionais ao estresse (ínsula direita e dorsolateral; córtex pré-frontal), por processamento sensorial (giro occipital médio) e pela função socioemocional (giro angular direito, fascículo uncinado e cingulado posterior, e para-hipocampal). Embora o grau com que essas associações refletem influências pós-natal não seja claro, ficou determinado que a ansiedade materna pré-natal prevê neurodesenvolvimento e psicopatologia da prole $^{16}$.

Diante da observação de que um genoma pode constituir diferentes epigenomas e de que fatores ambientais estão diretamente ligados a esse processo, quer por efeitos epigenéticos transgeracionais, quer via herança gamética epigenética ${ }^{17}$, estudos como os de Non et al. $(2014)^{18}$ ganham ainda mais notoriedade.

Em seus estudos, os referidos autores demonstraram que pequenas diferenças na metilação do DNA de recém-nascidos expostos à ansiedade/depressão materna não medicada ou expostos ao uso de antidepressivos durante a gravidez, perante os recém-nascidos não expostos a quaisquer dessas situações, sugerem a participação de processos epigenéticos no desenvolvimento do grupo de neonatos expostos sem uso de medicação.

Além dos mecanismos de modificação das histonas, do silenciamento de RNA e do Imprinting, a metilação do DNA tem se tornado mecanismo conhecido de regulação epigenética. Efeitos epigenéticos do estresse via alteração dos padrões de metilação do DNA sobre o eixo hipotálamo-hipófise-adrenal e sobre a neurotransmissão e neuroplasticidade cerebral demonstram que a perturbação de seu controle dinâmico fisiológico pode ser prejudicial à saúde mental ${ }^{19}$.

No estudo de Murphy et al. $(2015)^{20}$, níveis globais elevados de metilação do DNA foram encontrados em indivíduos ansiosos, comparativamente ao grupo controle. Além disso, foi observada expressão aumentada dos genes DNMT 1/ 3A (DNA metiltransferase), EZH2 (proteína indutora da metilação de histonas) e da IL-6 (citocina inflamatória) em indivíduos com maior pontuação na escala de ansiedade. Tais dados suportam a hipótese de que alterações nos perfis de metilação do DNA podem contribuir para a biologia da ansiedade e que esta está associada a níveis elevados de citocina inflamatória.

O cérebro é o órgão central de percepção e resposta do corpo ao estresse. Tanto o cérebro juvenil quanto o adulto mostram uma capacidade fisiológica significativa para a plasticidade estrutural e comportamental duradoura consequente a essa exposição/ resposta. Hunter et al. (2013) ${ }^{21}$, sob a mesma vertente de pensamento dos estudos anteriormente citados, defendem, assim, a relevância dos mecanismos epigenéticos na alteração de resposta ao stress, da ansiedade e plasticidade cerebral ao longo da vida e para além de sucessivas gerações.

\section{DISCUSSÃO}

Nos quadros de transtornos de ansiedade, os ajustes fisiológicos, aos quais o organismo se torna submetido, extrapolam o âmbito do sistema nervoso autônomo e atingem o sistema endócrino e imunitário, tornando-se mais duradouros.

A presente revisão torna-se, assim, relevante, ao reunir estudos que revelaram que a prática de exercícios físicos tem demonstrado importante papel na modificação do curso dos principais sinais e sintomas que envolvem tais fenômenos ansiosos. As variáveis de estudo bastante distintas entre si (com relação ao tamanho populacional do grupo amostral, à idade média dos participantes, ao condicionamento físico de cada integrante e ao tipo de exercício físico proposto), dificultaram interpretações mais específicas acerca da temática proposta.

Nesse sentido, apesar de se conseguir comprovar o notório impacto positivo da prática de exercícios físicos em funções neuropsíquicas, não é possível delinear com exatidão o melhor perfil a ser proposto, a fim de se obter tais benefícios.

No que se refere à influência transgeracional das características epigenéticas em quadros de transtornos de ansiedade, concluise que, mais que atuar como importante ferramenta promotora de regulação de genes, a epigenética associa-se direta ou indiretamente a todas as transformações morfofisiológicas estudadas e se correlaciona de maneira intensa aos quadros de transtorno de ansiedade.

Finalmente, há evidência de que o exercício físico influencia a saúde mental - especialmente a evolução e o desfecho dos distúrbios de ansiedade. Há um crescente interesse pela epigenética e pelo treinamento de força, embora haja baixo índice de artigos científicos que interliguem esses elementos. 
Estudos que busquem correlacionar o papel transgeneracional das características epigenéticas em condições neuropsiquiátricas são, cada vez mais, necessários para otimização das condutas e da atuação dos profissionais envolvidos nesse contexto.

\section{REFERÊNCIAS}

1. McGauch JL, Weinberger NM, Whalen RE. Psicobiologia: as bases biológicas do comportamento. Rio de Janeiro: Livros Técnicos e Científicos; 1977.

2. Selye H. Stress without distress. Philadelphia: JB Lippincott; 1974.

3. American Psychiatric Association. Manual diagnóstico e estatístico de transtornos mentais: DSM-5. 5. ed. Porto Alegre: Artmed; 2014.

4. Antunes HK, Stella SG, Santos RF, Bueno OFA, Mello MT. Depression, anxiety and quality of life scores in seniors after an endurance exercise program. Rev Bras. Psiquiatr. 2005 Dec; 27(4): 266-71. doi: http://dx.doi.org/10.1590/S151644462005000400003.

5. Araújo SRC, Mello MT, Leite JR. Transtornos de ansiedade e exercício físico. Rev Bras Psiquiatr. 2007 Nov; 29(2):164-71. doi: http://dx.doi.org/10.1590/ S1516-44462006005000027.

6. Veigas J, Gonçalves M. A influência do exercício físico na ansiedade, depressão e stress [Internet]. Portugal: Psicologia.PT; 2009 [acesso em 2015/09/15]. Disponível em: http://www.psicologia.pt/artigos/ver_artigo. php?codigo=A0485.

7. Tibana RA, Prestes J. Treinamento de Força e Síndrome Metabólica: uma revisão sistemática. Rev Bras Cardiol. 2013; 26(1):66-76.

8. Brown SE, Fraga MF, Weaver IC, Berdasco M, Szyf M. Variations in DNA methylation patterns during the cell cycle of HeLa cells. Epigenetics. 2007 JanMar; 2(1):54-65. PubMed PMID: 1796591.

9. Kangaspeska S, Stride B Métivier R, Polycarpou-Schwarz M, Ibberson D, Carmouche RP, et al. Transient cyclical methylation of promoter DNA. Nature. 2008 Mar; 452(7183): 112-115. doi: 10.1038/nature06640. PubMed PMID: 18322535.

10. Métivier R1, Gallais R, Tiffoche C, Le Péron C, Jurkowska RZ, Carmouche RP, et al. Cyclical DNA methylation of a transcriptionally active promoter. Nature. 2008 Mar;452(7183):45-50. doi: 10.1038/nature06544. PubMed PMID: 18322525.

11. Lent R. Cem bilhões de neurônios: conceitos fundamentais de neurociência. São Paulo: Atheneu; 2005.

12. Cid L, Silva C, Alves J, Atividade física e bem-estar psicológico - perfil dos participantes no programa de exercício e saúde de rio maior. Motri. 3(2): 47-55, 2007.

13. Matsudo SM, Matsudo VKR, Barros TL Neto. Efeitos benéficos da atividade física na aptidão física e saúde mental durante o processo de envelhecimento. Revista Brasileira de Atividade Física e Saúde. 2000; 5(2): 60-76. doi: HTTP:// DX.DOI.ORG/10.12820/RBAFS.V.5N2P60-76.

14. Liu C, Chung M. Genetics and epigenetics of circadian rhythms and their potential roles in neuropsychiatric disorders. Neurosci Bull. 2015; Feb; 31(1):141-59. doi: 10.1007/s12264-014-1495-3.

15. Babenko O, Kovalchuk I, Metz GA. Stress-induced perinatal and transgenerational epigenetic programming of brain development and mental health. Neurosci Biobehav Rev. 2015 Jan; 48: 70-91. doi: 10.1016/j. neubiorev.2014.11.013.

16. Rifkin-Graboi A, Meaney MJ, Chen H, Bai J, Hameed WB, Tint MT, et al. Antenatal maternal anxiety predicts variations in neural structures implicated in anxiety disorders in newborns. J Am Acad Child Adolesc Psychiatry. 2015 Apr; 54 (4): 313-21. doi: 10.1016/j.jaac.2015.01.013.
17. Whitelaw E. Sins of the fathers, and their fathers. Eur J Hum Genet. 2006 Feb; 14(2):131-132. doi: 10.1038/sj.ejhg.5201567.

18. Non AL, Binder AM, Kubzansky LD, Michels KB. Genome-wide DNA methylation in neonates exposed to maternal depression, anxiety, or SSRI medication during pregnancy. Epigenetics. 2014 Jul; 9(7):964-72. doi: 10.4161/ epi.28853.

19. Hing B, Gardner C, Potash JB. Effects of Negative Stressors on DNA Methylation in the Brain: Implications for Mood and Anxiety Disorders. Am J Med Genet B Neuropsychiatr Genet. 2014 Oct; 165B(7): 541-54. doi: 10.1002/ ajmg.b.32265

20. Murphy TM, O'Donavan A, Mullins N, O’Farrelly C, McCann A, Malone K. Anxiety is associated with higher levels of global DNA methylation and altered expression of epigenetic and interleukin-6 genes. Psychiatr Genet; 2015 April; 25(2):71-8. doi: 10.1097/YPG.0000000000000055.

21. Hunter RG, McEwen BS. Stress and anxiety across the lifespan: structural plasticity and epigenetic regulation. Epigenomics 2013 Apr; 5(2):177-94. doi: 10.2217/epi.13.8

22. Bessa IR, Dode MAN. Ovogênese e modificações epigenéticas. Rev. Bras. Reprod. Anim. 2013 Jul-Set; 37(3): 241-248.

23. Booth FW, Chakravarthy MV, Gordon SE, Spangenburg EE. Waging war on physical inactivity: using modern molecular ammunition against an ancient enemy. J Appl Physiol (1985). 2002 Jul; 93(1): 3- 30. PubMed PMID: 12070181.

24. Braga JEF, Pordeus LC, Silva ATMC, Pimenta FCF, Diniz FMMF, Almeida RN. Ansiedade patológica: Bases neurais e avanços na abordagem psicofarmacológica. R Bras Ci Saúde. 2010;14(2):93-100. doi:10.4034/ RBCS.2010.14.02.13.

25. Cevada T, Cerqueira LS, Moraes HS, Santos TM, Pompeu FAMS, Deslandes ACD. Relação entre esporte, resiliência, qualidade de vida e ansiedade. Rev Psiq Clín. 2012;39(3):85-9. doi: http://dx.doi.org/10.1590/S0101 60832012000300003.

26. Freitas AR, Carneseca EC, Paiva CE, Paiva BSR. Impacto de um programa de atividade física sobre a ansiedade, depressão, estresse ocupacional e síndrome de Burnout dos profissionais de enfermagem no trabalho. Rev. Latino-Am. Enfermagem. Mar-Abr 2014; 22(2):332-6. doi: http://dx.doi.org/10.1590/01041169.3307.2420.

27. Graeff FG, Netto CF, Zangrossi H Jr. The elevated T-maze as an experimental model of anxiety. Neuroscience and Biobehavioral Rev. 1998; 23 (2):237-46. PubMed PMID: 9884116.

28. Graeff FG, Zangrossi H Jr. Serotonin in anxiety and panic: contributions of the elevated T-maze. Neurosci Biobehav Rev. 2014 Oct; 46 (Pt 3): 397-406. doi: 10.1016/j.neubiorev.2014.03.007.

29. Montero-Marín J, Asún S, Estrada-Marcén N, Romero R, Asún R. Effectiveness of a stretching program on anxiety levels of workers in a logistic platform: a randomized controlled study. Aten primaria. 2013 Aug-Set; 45(7):376-383. doi: 10.1016/j.aprim.2013.03.002

30. Mello MT, Boscolo RA, Esteves AM, Tufik S. O exercício físico e os aspectos psicobiológicos. Rev Bras Med Esporte. 2005 Maio-Jun; 11(3): 203-207. doi: http://dx.doi.org/10.1590/S0101-60832013000200004.

31. Minghelli B, Tomé B, Nunes C, Neves A, Simões C. Comparação dos níveis de 
ansiedade e depressão entre idosos ativos e sedentários. Rev Psiq Clín. 2013; 40(2):71-6. doi: http://dx.doi.org/10.1590/\$0101-60832013000200004.

32. Pinheiro SH, Zangrossi H Jr, Del-Ben CM, Graeff FG. Elevated mazes as animal models of anxiety: effects of serotonergic agentes. An Acad Bras Cienc. 2007 Mar; 79(1):71-85. doi: http://dx.doi.org/10.1590/S0001-37652007000100010.

33. Sadock BJ, Sadock VA. Compêndio de Psiquiatria: ciência do comportamento e psiquiatria clínica. Porto Alegre: Artmed; 2007.

34. Tian QU, Studenski SA, Resnick SM, Davatzikos C, Ferrucci L. Midlife and late-life cardiorespiratory fitness and brain volume changes in late adulthood: results from the baltimore longitudinal study of aging. J Gerontol A Biol Sci Med Sci. 2016 Jan; 71(1): 124-30. doi: 10.1093/gerona/glv041.

35. Torrejais JC, Rosa CM, Boerngen-Lacerda R, Andreatini R. The elevated
T-maze as a measure of two types of defensive reactions: a factor analysis. Brain Res Bull. 2008 Jul; 76(4): 376- 379. doi: 10.1016/j.brainresbull.2008.03.016.

36. Modolo VB, Mello MT, Gimenez PRB, Tufik S, Antunes HKM. Dependência de exercício físico: humor, qualidade de vida em atletas amadores e profissionais. Rev Bras Med Esporte. 2009 Set-Out; 15(5). doi: http://dx.doi.org/10.1590/ S1517-86922009000600007.

37. Wearick S, Luis Eduardo. Efeitos do exercício físico na memória e comportamento ansioso de camundongos expostos à separação materna [dissertação]. Porto Alegre (RS): Pontifícia Universidade Católica do Rio Grande do Sul; 2015.

38. Weslley QAS, Browne RAV. Nível de aptidão aeróbia e ansiedade físico-social em adultos jovens. Rev Bras Pres Fisio Exercício. 2014. Jul-Ago; 8(48): 589-593.

\section{Como citar este artigo/How to cite this article:}

Lobo MO, Krier FC, Tibana RA, Prestes J. Epigenética e exercício físico: influência em transtornos de ansiedade?. J Health Biol Sci. 2018 Abr-Jun; 6(2):182188. 